Department of Cardiology, Sri Jayadeva Institute of Cardiovascular Sciences and Research, Bangalore, Karnataka, India

\section{Correspondence to}

Dr Navin Agrawal,

drnavinagrawal@gmail.com

Accepted 20 April 2014

\title{
Dramatic recovery of chronic non-healing ulcer secondary to recurrent unprovoked DVT by venous stenting
}

\author{
Budnur C Srinivas, Vikram B Kolhari, Navin Agrawal, Babu Reddy
}

\section{DESCRIPTION}

Common causes of pelvic venous outflow obstruction include deep venous thrombosis (DVT) and extrinsic compression of the iliac veins. Recurrent DVT can cause venous stasis dermatitis, ulceration and thrombophlebitis and risk of pulmonary thromboembolism which can be life-threatening.

We present an interesting case of a 38 -year-old man who had undergone venous grafting in the past and had a history of recurrent left lower limb DVT. He presented to us with a non-healing ulcer over the left shin (figure 1) for the past 2 years with pain in the calf since 2 weeks. The peripheral pulses were normal and good volume and the ankle-brachial index was normal which essentially ruled out the possibility of an arterial disease.

A popliteal venogram (figure $2 \mathrm{~A}$ and video 1 ) showed thrombosis of the deep venous system up to the junction of the left common iliac vein (CIV) and the inferior vena cava (IVC). The patient had no obvious risk factors for recurrent DVT, and the thrombophilia workup which included evaluation for bleeding and coagulation parameters and factor $\mathrm{C}$, factor $\mathrm{S}$ and antiphospholipid antibody was negative. Diagnosis of acute on chronic DVTwas contemplated.

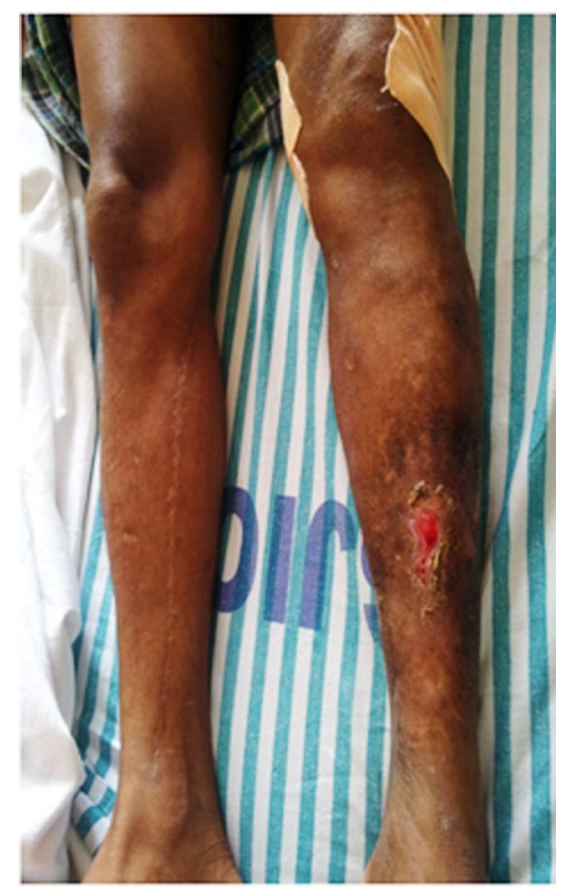

Figure 1 Non-healing ulcer over shin.
To cite: Srinivas $B C$ Kolhari VB, Agrawal N, et al. BMJ Case Rep Published online: [please include Day Month Year] doi:10.1136/bcr-2014204145
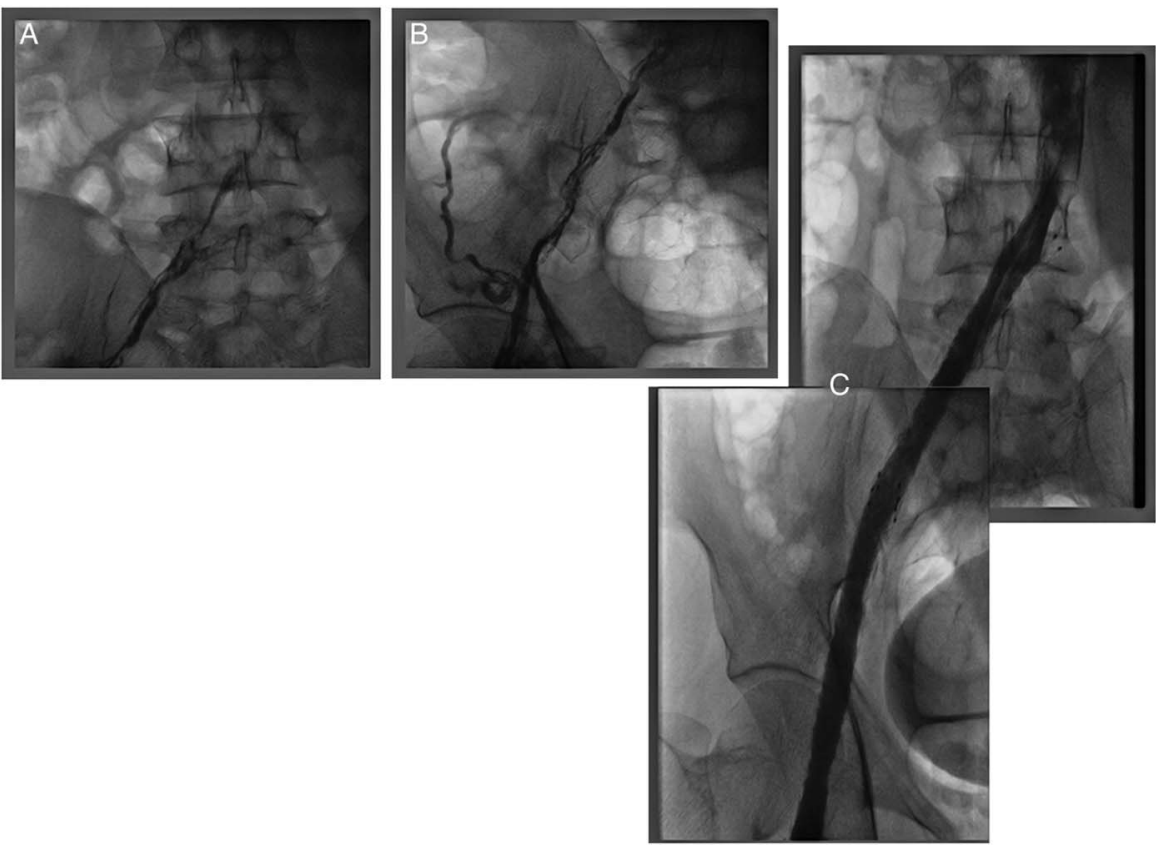

Figure 2 (A) Baseline venogram showing thrombosis of the deep venous system up to the junction of the left common iliac vein and the inferior vena cava. (B) Check venogram after catheter-directed thrombolysis showing significant thrombus. (C) Venogram after stenting showing good flow. 


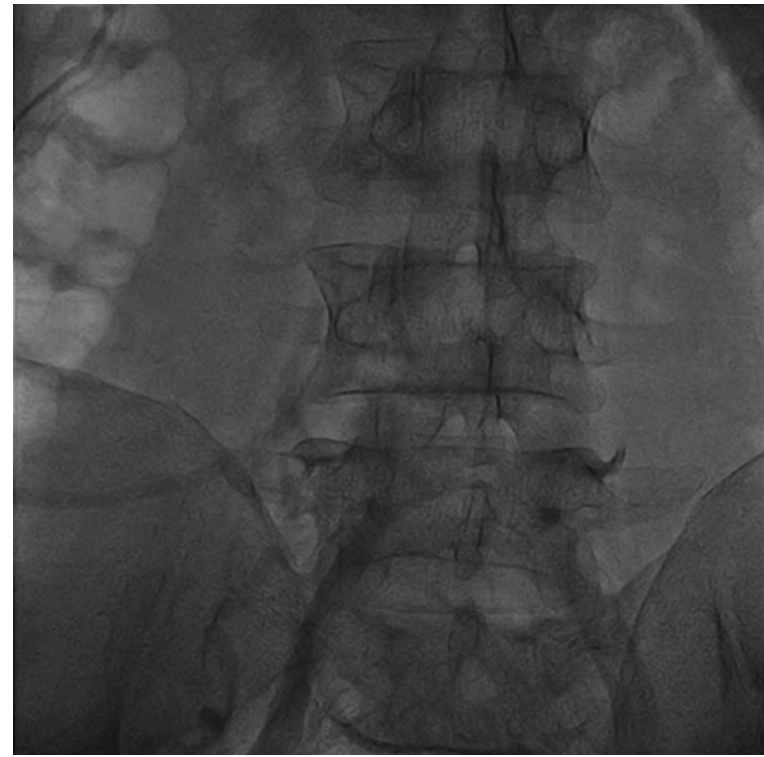

Video 1 Prone position venogram showing thrombus filled vein with restricted flow.

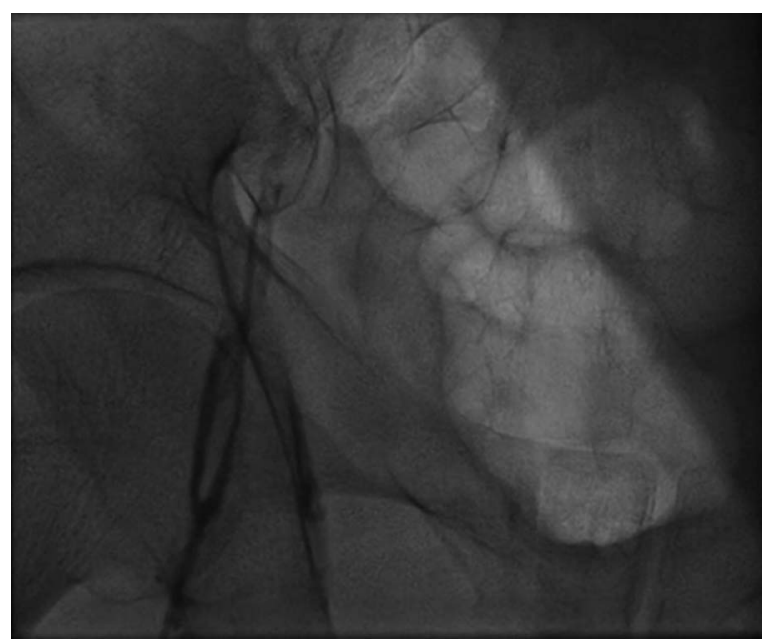

Video 2 Check venogram after catheter guided thrombolysis showing failed lysis and lack of antegrade flow.

A catheter-directed thrombolysis with the tip in the left femoral vein failed to restore good flow on the check venogram (figure 2B and video 2). A $0.018^{\prime \prime}$ terumo guide-wire was passed (video 3 ) into the IVC and the CIV was dilated with a $7 \times 60 \mathrm{~mm}$ peripheral balloon. Two nitinol self-expanding peripheral stents $(12 \times 80$ and $12 \times 120 \mathrm{~mm})$ were deployed across the left CIV and the external iliac vein. Good flow was achieved after the procedure (figure 2C, videos 4 and 5) and the venous ulcer healed (figure 3) within a week.

Immediate management of an acute episode of DVT involves systemic anticoagulation or thrombolysis followed by long-term prophylactic oral anticoagulation. Percutaneous intervention can be life-saving and can improve the quality of life and can provide a long-lasting and uncomplicated outcome. ${ }^{1-4}$

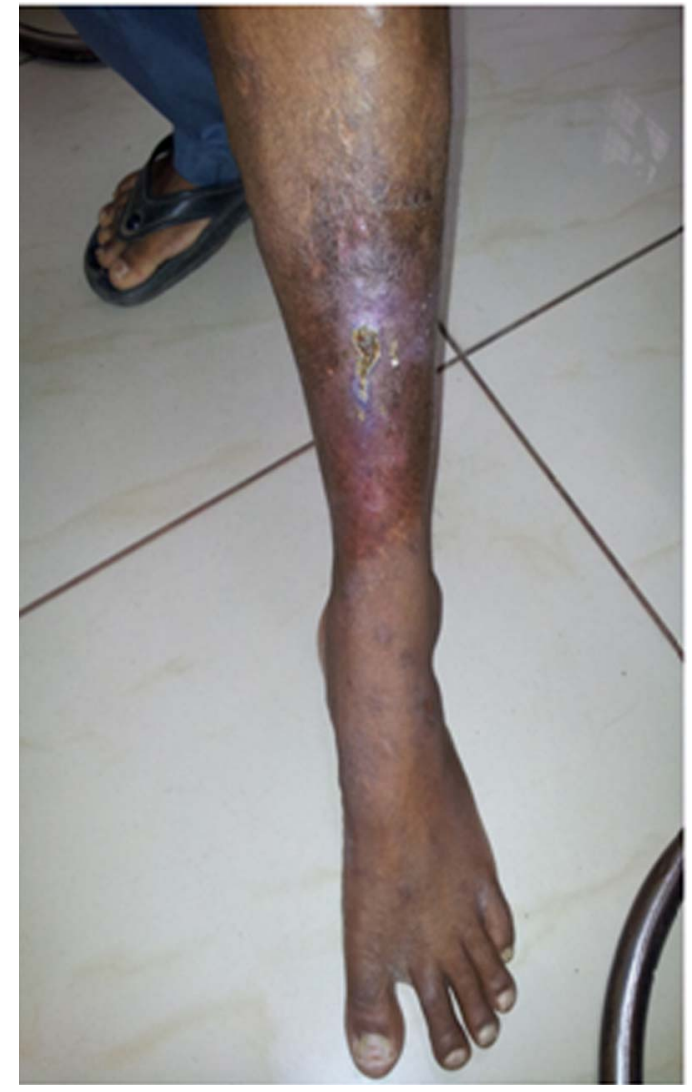

Figure 3 Successful healing of the ulcer post-stenting.

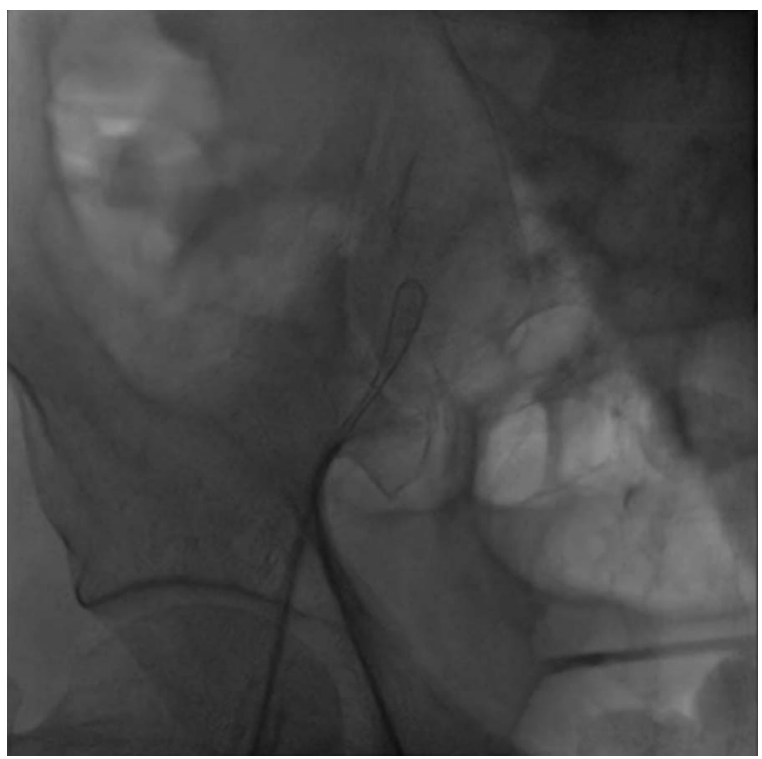

Video 3 A 0.018' terumo guide-wire was passed into the IVC and the CIV 


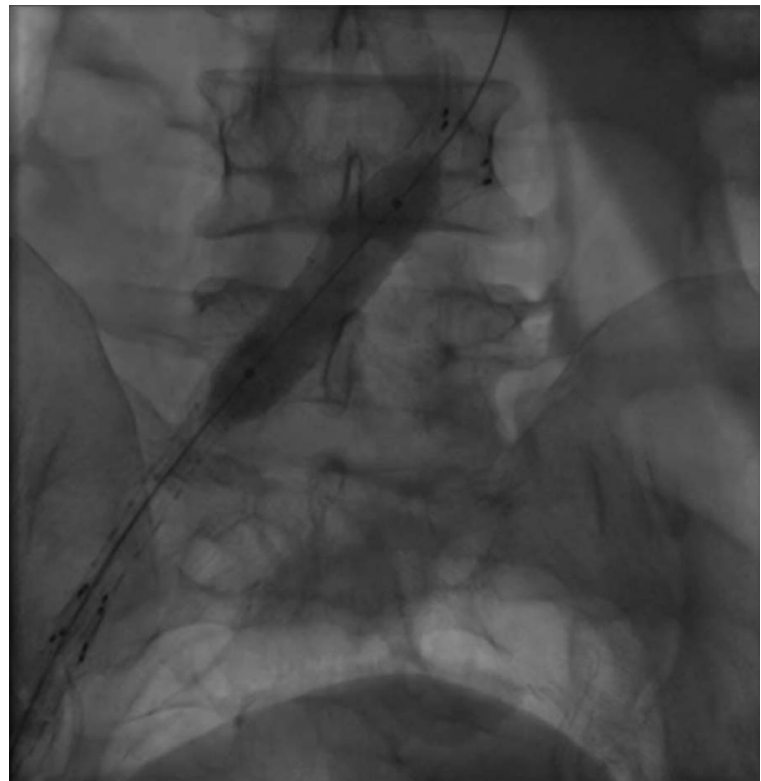

Video 4 Two nitinol self-expanding peripheral stents $(12 \times 80$ and $12 \times 120 \mathrm{~mm}$ ) were deployed across the left CIV and the external iliac vein.

\section{Learning points}

- Common causes of pelvic venous outflow obstruction include deep venous thrombosis (DVT) and extrinsic compression of the iliac veins. Recurrent DVT can cause dermatitis, ulceration and risk of embolism.

- Thrombolytic therapy forms the first line of intervention for most patients with uncomplicated DVT unless there are obvious contraindications to lysis.

- A venous stent is usually indicated for residual stenosis after thrombolysis or in some cases of extrinsic compression and if performed successfully it provides uncomplicated outcomes and rapid healing of venous ulcers in appropriately selected cases.

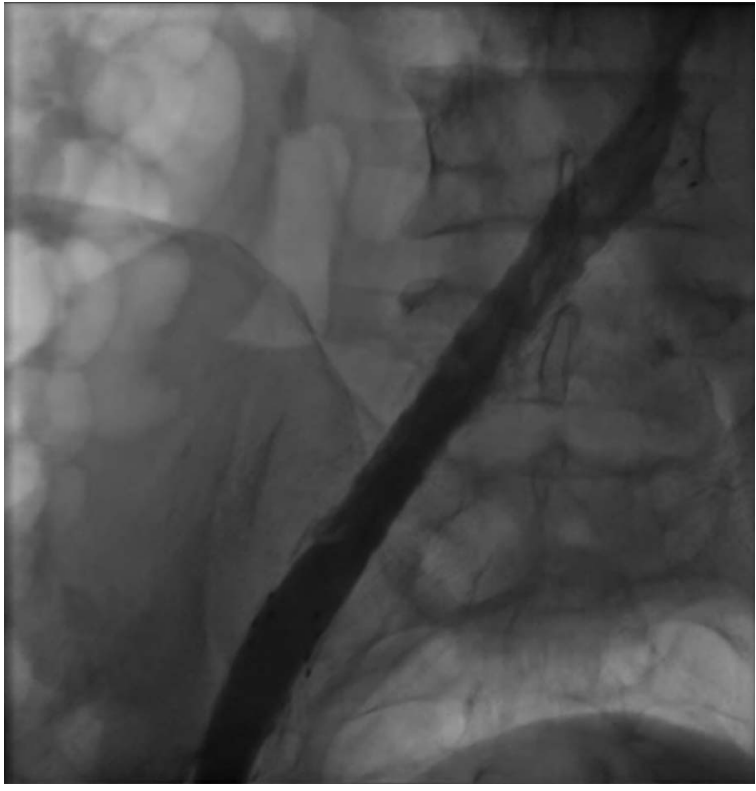

Video 5 Good flow was achieved after post dilation

Competing interests None.

Patient consent Obtained.

Provenance and peer review Not commissioned; externally peer reviewed.

\section{REFERENCES}

1 Neglen P, Thrasher TL, Raju S. Venous outflow obstruction: an underestimated contributor to chronic venous disease. J Vasc Surg 2003;38:879-85.

2 Mussa FF, Peden EK, Zhou W, et al. Iliac vein stenting for chronic venous insufficiency. Tex Heart Inst J 2007;34:60-6.

3 ÊDelis KT, Bjarnason $\mathrm{H}$, Wennberg PW, et al. Successful iliac vein and inferior vena cava stenting ameliorates venous claudication and improves venous outflow, calf muscle pump function, and clinical status in post-thrombotic syndrome. Ann Surg 2007;245:130-9.

4 Êvedantham S, Thorpe PE, Cardella JF, et al. Quality improvement guidelines for the treatment of lower extremity deep vein thrombosis with use of endovascular thrombus removal. J Vasc Interv Radiol 2006;17:435-47; quiz 448.

Copyright 2014 BMJ Publishing Group. All rights reserved. For permission to reuse any of this content visit http://group.bmj.com/group/rights-licensing/permissions.

BMJ Case Report Fellows may re-use this article for personal use and teaching without any further permission.

Become a Fellow of BMJ Case Reports today and you can:

- Submit as many cases as you like

- Enjoy fast sympathetic peer review and rapid publication of accepted articles

- Access all the published articles

- Re-use any of the published material for personal use and teaching without further permission

For information on Institutional Fellowships contact consortiasales@bmjgroup.com

Visit casereports.bmj.com for more articles like this and to become a Fellow 